\title{
Dynamics of Spirulina In Promoting Health Benefits For Arsenicosis Patients
}

\author{
MH RAHMAN ${ }^{\mathrm{a}}$, AZM M ISLAM $^{\mathrm{b}}, \mathrm{S}^{\text {SIKDER }}{ }^{\mathrm{c}}$
}

\begin{abstract}
Summary:
A total number of 40 patients affected with arsenicosis were selected and clinically examined prior to feeding trials. The interrelatedness between improvement respondents following spirulina intake in respect of age, sex, nutrition and social condition of patients exposed to arsenic contaminated water was evidenced. Among sexwise respondents about $62 \%$ females showed improvement in comparison to $58.3 \%$ males. The spirulina intake caused more improvements in age group 15-35 years (66.66\%) than patients of 35 to 55 years (50\%). The impact of spirulina improvement showed a different vulnerability of social taboos. It occurred $71.42 \%$ in middle class, while in poor class this was $69.29 \%$. The greatly vulnerable poverty related malnourished arsenicosis patients responded to therapy equally as attained by well nourished patients. The overall response
\end{abstract}

Introduction:

With more than an estimated 20 million of its 125 million people assumed to be drinking arsenic contaminated water, Bangladesh is facing, what is perhaps the largest poisoning in history. According to WHO some 70 million people are alarmingly at risk of consuming arsenic contaminated water of tube wells, the main source of portable water of the 60 out of 64 districts ${ }^{1}$. The vibration 'arsenic engulfing Bangladesh' has recently been highlighted in the report of the United Nations University (UNU) in

a. Dr. Muhammad Hasibur Rahman, FCPS, Assistant professor, Dermatology and Venereology, Community based medical college, Mymensingh, Bangladesh

b. Professor Dr. A.Z.M. Maidul Islam, MBBS, DD (Dhaka), AEL (Paris), DTAE (Paris), AESD \& V (Paris), FAAD (USA), Chairman, Department of Dermatology and Venereology, Bangabandhu Sheikh Mujib Medical University (BSSMU), Dhaka, Bangladesh

c. Dr. M.S.Sikder, Associate Professor, Department of Dermatology and Venereology, Bangabandhu Sheikh Mujib Medical University (BSSMU), Dhaka, Bangladesh

Address for correspondence: Dr. Muhammad Hasibur Rahman, FCPS, Assistant professor, Dermatology and Venereology, Community Based Medical College, Mymensingh, Bangladesh.

Received: 9 July, 2006

Accepted: 7 March, 2007 revealed that $60 \%$ patients showed improvement with spirulina treatment which was statistically highly significant $(x 2=8.64$ at $P<0.01)$.

The viability of spirulina to offer health benefits to arsenicosis patients proved considerably satisfactory, because there was significant improvements of general health in all patients who received spirulina during the experimental period. Although 60 to $70 \%$ recovery has been recorded with spirulina intake in arsenicosis patients, but it is still interesting to note that the drug assisted remedy from malnutrition and might have boosted up the immune system. The present research study evidenced that arsenic, which induces cellular toxicity, could be prevented by treatment with known supportive treatment, such as spirulina along with other antioxidants.

(J Bangladesh Coll Phys Surg 2008; 26: 14-21)

Tokyo and the Dhaka based Earth Identity Project prompted recognition of its major impacts affecting agriculture and other related industries, water management, public health and overall national economy 2,3

Arsenic acts as a silent killer which is undetectable in its early stage of arsenic poisoning and takes between 8 and 14 years to impact on the health depending on the amount of arsenic ingested, nutritional status and immune response of the individual ${ }^{4,5}$, and 6.7. To date, several thousands of patients with arsenic related skin diseases have been found in the first limited surveys ${ }^{2}$.Bangladesh Government is however promoting surveillance and helping to strengthen data collection and Bangladesh Arsenic Mitigation and Water Sanitation Project (BAMWSP) is focusing on risk reduction strategies Drugs used for chelating arsenic in chronic Arsenicosis are tried. Use of antioxidants has shown evidences of improvement and topical use of salicylic acid has been found effective in reducing pain and roughness of keratosis ${ }^{8}$. Recently Spirulina, blue-green algae developed by Bangladesh and French scientists has been found to have very good effects on people suffering from 
Arsenicosis 9 and 10 . Leading dermatologists of the country unanimously recommended Spirulina to treat arsenic patients ${ }^{11}$.

The present research study undertaken focuses on the future use of Spirulina in the diet program for general maintenance, supportive treatment and nutritional improvement. The chief objective is to confirm whether arsenic patients given Spirulina show significant improvement and exhibit potential health benefits.

\section{Material and method:}

Type of study: The type of study undertaken was based upon randomized sampling and observational double blind trial

Duration of study: six months

Study population: A total number of 40 patients having suspected skin lesions of Arsenicosis were selected randomly during the period of January 2004 to July 2004 at the Dermatology Venereology Department of Bangabandhu Sheikh Mujib Medical University (BSMMU), Dhaka, Bangladesh.

Patients'selection: Patients who attended the arsenic clinic belonging to the Department of Dermatology and Venereology of Bangabandhu Sheikh Mujib Medical University with typical clinical manifestation of chronic arsenicosis as per standard instruction and recommendation.

\section{Inclusion criteria:}

1. Patients who had given verbal consents and were willing to comply with this study process

2. Arsenicosis patients of both sex groups between 15 to 55 years

3. Patients who did not receive any treatment (either systemic or topical) prior to one month of the study

4. Patients having history of consumption of arsenic contaminated water

5. Patients who had hyper-pigmentation or leukomelanosis in the trunk and extremities, keratosis in palms and soles and other typical signs and symptoms of chronic arsenicosis

\section{Exclusion criteria:}

1. Patients who refused to be included in the study

2. Patients having age below 15 years and above 55 years of age
3. Pregnant women and lactating mothers

4. Arsenicosis with complications and malignancy

5. Patients who are to take regular antibiotics or steroids for other major systemic illnesses.

Pre-feeding examination: Clinical examination of arsenic affected patients prior to feeding trials

Post-feeding examination: Clinical examination of arsenic affected selected patients periodically after spirulina feeding trials.

Source of samples: Clinical samples of the study were obtained from selected patients belonging to affected areas under investigation

Collection and transportation of samples: Arsenicosis patients were asked either to come to the hospital or they were visited as per schedule of the study. Clinical samples for the study were collected and processed as per standard recommendation.

Feeding of spirulina samples: Spirulina samples in the form of capsule or other means were fed to 20 arsenicosis patients. Capsules were prepared as per recommendation. Spirulina samples manufactured by Lifeline International under the supervision of BCSIR Li No. Sachi/ppp1 (314)/90/4737) may be given in the form of 10-gram powder, dissolved in water, and given daily in divided doses.

Feeding of placebo: Placebo prepared similar to spirulina were fed to other 20 arsenicosis patients

\section{Method:}

Selection of patients: A total number of 40 patients affected with suspected arsenicosis were selected for this study. They were placed under two equal groups. The patients and physicians were fully unaware of the above treatments intended for the study. The patients for this study were between 18 to 55 years of age.

Data of information and history of pre-fed patients: Data of information were collected from all arsenic exposed patients prior to the above feeding trials and recorded.

Data of information and history of post-fed patients: In post-fed group both placebo and spirulina treated patients were subjected to analogous study as mentioned earlier in prefed patients. Here the clinical examination was performed after every 15 days of feeding trials. Comparative nature and extent of clinical manifestations appearing and other 
improvement occurring and not occurring were recorded. After every three months all postfed patients were examined to detect any changes in improvement. The duration of post-feeding was limited for one year.

Advice to patients: All 40 selected arsenic patients were advised to use strictly surface water for domestic works and take arsenic free drinking water during the total period of the study.

A checklist in the form questionnaire consisting of patients data was evaluated prior to feeding and after feeding. The questionnaire format is presented in fig 2 .

Grading of severity of chronic arsenicosis and assessment of response to spirulina:

This is done and evaluated by calculating the total scores obtained from 'Questionnaire format'. Ascending total scores indicate severity of infection, while descending scores refer to less to no infection. The numerical 0 indicates no clinical signs or symptoms or no improvement from spirulina. Negative signs of numericals, such as $-1,-2,-3,-4$ and -5 used indicate severity of infection as less severe, fairly severe, moderately severe, severe and highly severe respectively. Analogously the degree of improvement from spirulina treatment is calculated using the positive numericals, such as $+1,+2,+3,+4$ and +5 which stand for less, slight or partial, moderate, good and very good improvement. The total score allotted for 20 clinical features are 100 , each feature having maximum of 5 scores. Improvement is noticed when the total score after treatment ranges between 1 to 100 and no improvement was recorded when the total score was 0 and the difference of evaluation before and after treatment stands between 0 and -100 .

Diagrammatic illustration of the research plan: The plan of the research is presented below diagrammatically in figure 1 .

Statistical analysis was done in which clinical scores were evaluated. Frequency distribution, Chi square test, Yate's correction and other software were employed for determining significant correlation between observations

Response to treatment: Clinical examination of arsenic affected patients prior to treatment trials was recorded. Patients were clinically examined for noticing any improvement that occurred after every two weeks. Nutritional status of patients was assessed using MAC (mid arm circumference) value.

\section{Result:}

The present study demonstrated the interrelatedness between improvement of respondents following spirulina intake and age, sex, nutrition and social condition of arsenicosis patients exposed to arsenic contaminated water. Table 1 represented that the impact of responses of patients to spirulina differed among male and female personnel. The sex-wise distribution of respondents to the treatment of arsenicosis with spirulina evidenced that about $62 \%$ females exhibited improvement in comparison to $58.3 \%$ males. None of the females got improvement with placebo treatment, whereas $20 \%$ males got some improvement.

Table- I

Sex-wise respondents of chronic arsenicosis patients to spirulina treatment $(n=40)$

\begin{tabular}{lll} 
Treatment & $\begin{array}{l}\text { Improvement (\%) } \\
\text { in males }\end{array}$ & $\begin{array}{l}\text { Improvement }(\%) \\
\text { in females }\end{array}$ \\
\hline Placebo $(\mathrm{n}=20)$ & 21.48 & 0 \\
Spirulina $(\mathrm{n}=20)$ & 58.33 & 62.50 \\
\hline
\end{tabular}

It is evident from table 2 that the spirulina intake caused improvement in patients more in age group $15-35$ years $(66.66 \%)$ than patients of age group 35 to 55 years $(50 \%)$. The respondents to treatment with spirulina although was found about $16 \%$ more in younger age group, but with placebo treatment no obvious improvement occurred. The respondents with placebo treatment were $11.11 \%$ and $18.18 \%$ in older and younger age groups respectively.

\section{Table-II}

Age-wise respondents of chronic arsenicosis patients to spirulina treatment $(n=40)$

\begin{tabular}{lll} 
Treatment & $\begin{array}{l}\text { Improvement }(\%) \\
\text { in age group } \\
15-35 \text { years } \\
(\mathrm{n}=20)\end{array}$ & $\begin{array}{l}\text { Improvement }(\%) \\
\text { in age group } \\
36-55 \text { years } \\
(\mathrm{n}=20)\end{array}$ \\
\hline Placebo $(\mathrm{n}=20)$ & 18.18 & 11.11 \\
Spirulina $(\mathrm{n}=20)$ & 66.66 & 50.00 \\
\hline
\end{tabular}

The impact of arsenicosis on the susceptibility of the poor to arsenicosis and vulnerability to social taboos represent a different phenomenon, when the patients were given treatment with spirulina. The result is presented in table 3 . The spirulina improvement that occurred in middle class people was $71.42 \%$, while in poor class this was $69.29 \%$. In case of placebo treatment the socioeconomic class did not play any 
role in the improvement of arsenicosis patients. The percentage distributions of improvement recorded in poor class and middle class arsenicosis patients were 14.28 and 16.66 respectively.

\section{Table-III}

Relationship between Socioeconomic status of patients and spirulina intake $(n=40)$

Socio-economic Improvement (\%) Improvement ( $\%$ ) status of patients after Placebo after spirulina treatment $(\mathrm{n}=20) \quad$ treatment $(\mathrm{n}=20)$

$\begin{array}{lll}\text { Poor class } & 14.28 & 69.29\end{array}$

Middle class $\quad 16.66 \quad 71.42$

The interrelatedness of nutritional status and spirulina intake as presented in Table 4 demonstrated that the nutritional level of arsenicosis patients contributed to the response of improvement. The greatly vulnerable poverty related malnourished $60 \%$ arsenicosis patients responded to improvement equally as shown by $60 \%$ well nourished patients.
Table IV

Interrelatedness of nutritional status with spirulina intake of arsenicosis patients pas $(n=40)$

\begin{tabular}{lll}
$\begin{array}{l}\text { Nutritional } \\
\text { status }\end{array}$ & $\begin{array}{l}\text { Improvement (\%) } \\
\text { after Placebo } \\
\text { treatment }(\mathrm{n}=20)\end{array}$ & $\begin{array}{l}\text { Improvement }(\%) \\
\text { after spirulina } \\
\text { treatment }(\mathrm{n}=20)\end{array}$ \\
\hline Well nourished & 50 & 60 \\
Malnourished & 11.11 & 60 \\
\hline
\end{tabular}

The overall improvement and response of 40 chronic arsenicosis patients to treatment with spirulina are presented in table 5. It is worthy to note that $60 \%$ patients showed considerable improvement with spirulina treatment, whereas $15 \%$ patients got improvement with placebo treatment. It is clearly evident from $x^{2}$ test that there is a strong association between spirulina intake and improvement status among patients with arsenicosis. That is spirulina intake certainly caused improvement and the result is found statistically highly significant $\left(x^{2}=8.64\right.$ at $\left.\mathrm{P}<0.01\right)$

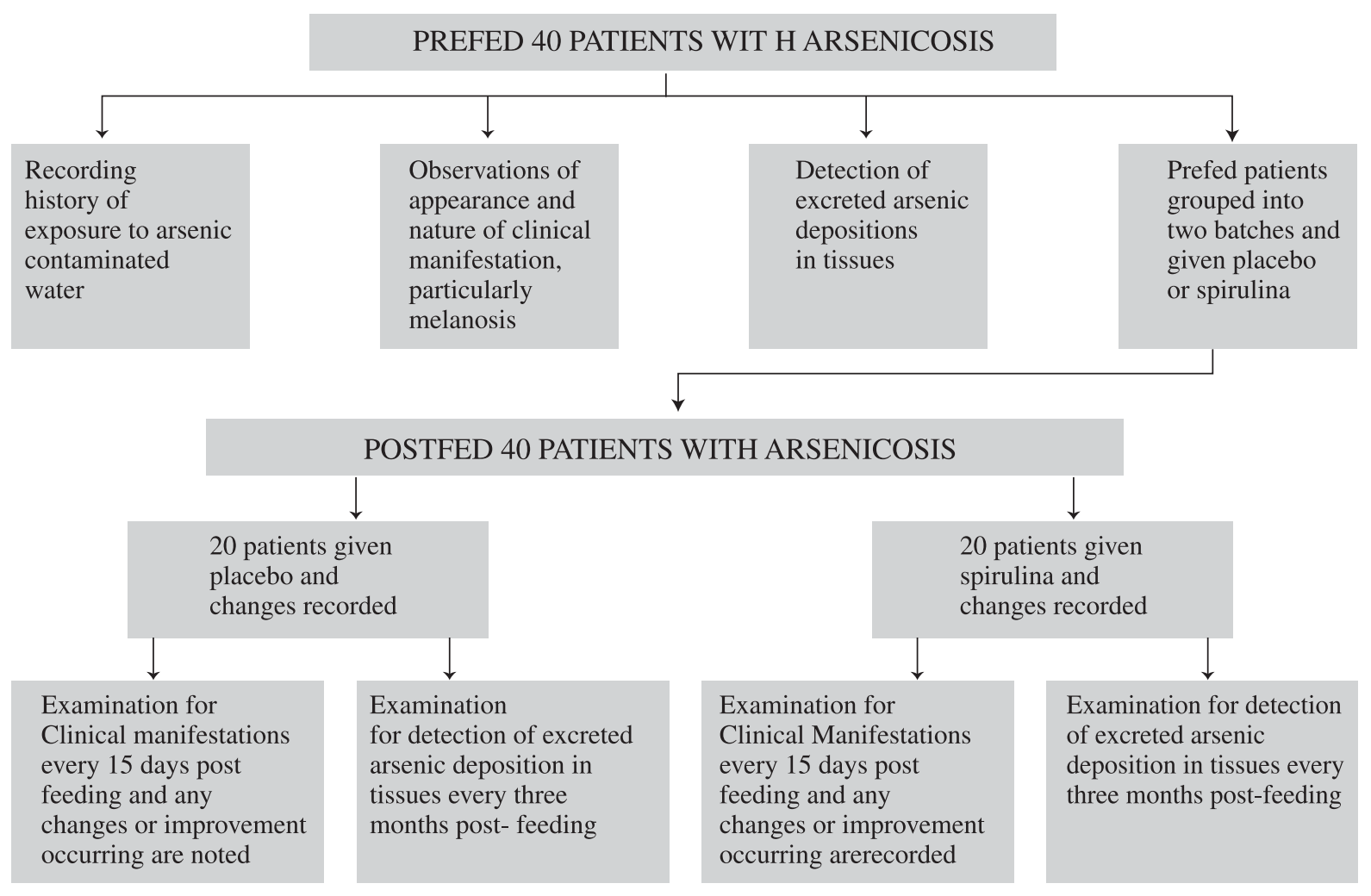

Fig.1: Schematic illustration of the experimental study 
Name

Source of drinking water

(Arsenic contaminated)
Age

'Y'Wt.

Socio-economic status:

a $\mathrm{H} / \mathrm{O}$ past illness (if any):

모 Drug history:

ㅁ Personal habit:
i poor class
i Middle class
i High class

Malnourished

- Hyper-pigmentation: O Scoring (1) Diffuse over palm and sole Raindrop pigmentation or leucomelanosis of upper trunk (3) Raindrop pigmentation in whole trunk

- Hyperkeratosis: o Scoring (1) Diffuse in palm and sole spotted keratosis, palm and sole

Marked spotted keratosis with fissuring and marked thickening

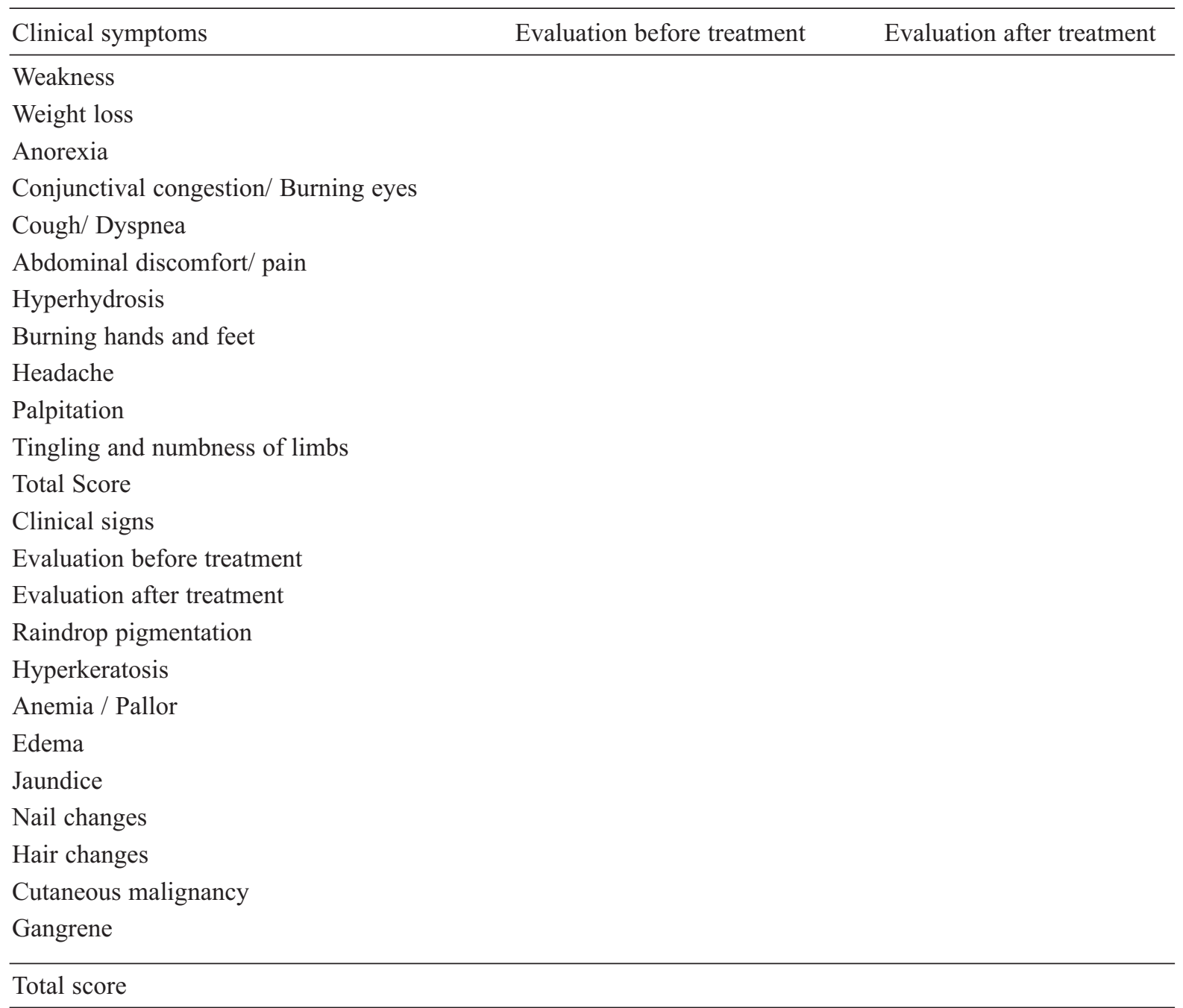

Fig.-2: Questionnaire Format 


\section{Discussion:}

Extensive pollution of the major drinking water source (underground tube well water) with high levels of arsenic has recently been recognized as an important public health hazard in Bangladesh ${ }^{12}$, as a result the incidence of morbidity and mortality associated with arsenicosis calamity is increasing day by day 13,14 and 15 . Since specific and useful treatment of chronic arsenicosis is still not available, Bangladesh researchers are seeking for effective therapeutic strategies to find out new modalities of treatment ${ }^{16}$. Recent development in molecular biology and the state-of-the-art-knowledge indicate that application of antioxidants (selenium, vitamin $\mathrm{C}$, vitamin $\mathrm{E}, \beta$-carotene etc) in the treatment of arsenic toxicity may be useful. The present study evaluates and validates the therapeutic efficacy and health benefit of the $\beta$-carotene containing spirulina in the treatment of chronic arsenicosis victims.

Spirulina (Arthrospira platensis) is a microscopic spiral shaped, blue green vegetable alga is the richest source of beta-carotene and mixed carotenoids in the world 17, 18 and 19. Scientific reports indicated that spirulina is nature's richest whole-food source of phytocyanin, an immune stimulant 8,20 and 21 . It has been consumed by millions of people of all ages in the U.S. and more than 40 countries for over 20 years.

Spirulina is now available in tablets, capsules and powder. The dark green powder can be blended into fruit and milk drinks or added to recipes to boost nutritional value. The administration of spirulina in the present study showed significant improvement without any notable toxicity. Khan et al ${ }^{22}$ led to opinions that the resultant clinical arsenicosis depends on chemical and physical form of the compound and the route by which it enters the body, the dose and the duration of exposure, age, sex and socioeconomic condition of the affected individuals. The result of this study evidenced that irrespective of age, sex, nutritional status and socio-economic category the spirulina caused about 60 to $70 \%$ improvement among individuals affected with chronic arsenicosis. Guha Mazumder ${ }^{23}$ earlier found that the high protein diet could play role in the alleviation of symptoms of arsenic poisoning, because it enhanced the excretion of arsenic in urine by increasing methylation in the body. Many researchers also demonstrated that the protein of spirulina might be beneficial in promoting cell growth and repairing the damage of liver and Kidney tissue.

The study undertaken revealed that the treatment orally with spirulina has been associated with clinical regression of arsenic keratosis. This improvement is due to the fact that spirulina contains high amount of gamma linoleic acid (GLA), which is a precursor for the body's prostaglandin in master hormone that controls many body functions. Rabbani at al 12 demonstrated that the parameters of arsenic toxicity and endogenous antioxidants could be brought towards normal or favorable conditions much better by giving a recipe of vitamins, zinc and selenium. Since spirulina is the nature's richest food source of entire antioxidant spectrum, including beta-carotene, vitamin E, selenium, methionine, copper, manganese, zinc, B-vitamin etc., it has therefore clearly proved that this protein diet has fought against the oxidizing free radicals caused by pollution, malnutrition, stress and injury to arsenicosis patients $10,24,25,26$ and 27

The detoxification goal of arsenic toxicity should be to neutralize the poison in the body or eliminate it from the body and repair the damage to organs and cells $^{12,28 \text { and } 29}$.It is revealed from the present study that arsenicosis patients belonging to older age group, 36 - 55 years improved a little more $(50 \%)$ than the younger patients of the group $15-35$ years $(33.33 \%)$ in the spirulina intake population. The explanation may be thought to be due to the fact that older people were more careful and responsible to take medicine and followed the health care instruction more appropriately than the younger. It may be believed that in the older age group the spirulina intake could have enhanced more bio-transformation of inorganic arsenic to less toxic organic arsenic, by rapid elimination of arsenic from the body and preventing tissue deposition and by increasing the ability of body's antioxidative defensive system

Studies on arsenicosis indicated that malnutrition increases the susceptibility to arsenicosis if the undernourished persons are exposed to arsenic contamination through drinking water. The therapeutic efficacy of spirulina in the treatment of arsenicosis patient suggested that malnourished patients showed marked improvement of their physical weakness and felt better after treatment. Similar improvement is found in reducing skin manifestations of arsenicosis patients who received 
spirulina $10,22,25$ and 27 . Recently the leading dermatologists of the country advocated for the beneficial effect of spirulina and recommended it as a great whole food alternative to isolated vitamins and minerals. It is already agreed by researchers 18,19 and 30 that spirulina contains the most remarkable concentration of nutrients known in any food, plant, grain or herbs.

As regards the sex-wise relationship with the beneficial effect of spirulina intake by chronic arsenicosis patients, it is clearly demonstrated in this study that the improvement occurred after treatment did not find any such relationship remarkably. Although most of the arsenic affected victims are males of low income group was recorded by Watanabe et $\mathrm{al}^{31}$, but Ali et $\mathrm{al}^{32}$ found more social awareness among females on arsenic contamination of water as assessed by Huq et al ${ }^{33}$, which revealed that more females $(32.58 \%)$ than male respondents $(27.27 \%)$ could mention the cardinal signs of arsenicosis correctly. Interestingly more female personnel (70.99\%) opined correctly that arsenic contamination is a problem of considerable length than the males $(41.82 \%)$. This awareness among females' amounts to more mobilizing for avoiding the source of arsenic contaminated tube well water. The women after receiving treatment with spirulina used surface water for washing, cooking and other domestic works. The response of spirulina treatment was more or less same in both sexes, revealing the fact that low social status in the family or low education or low income of the females cannot be justified to be correlated with the improvement of treatment, rather the consciousness or awareness plays vital role in getting remedy from arsenicosis.

The result of the present study and reports available from earlier workers ${ }^{10,26,33}$ evidenced that the use of spirulina showed significant symptomatic improvement without any notable toxicity. Moreover it can be consumed easily by mixing with rice or any other foodstuff. The in-vitro study of Chowdhury et al 26 has clearly shown that spirulina could act as a chelating agent when arsenic containing urine is passed through a column chromatography containing spirulina. Momtaj and Hussein 27 indicated a hospital based clinical trial with spirulina and demonstrated improvement in reducing skin manifestations of patients of arsenicosis who received $10 \mathrm{gm}$ spirulina daily for four months. It was further found that higher dosage of such drug for outpatients and shorter recovery times might be possible.

Since spirulina intake has proved to offer health benefits for problems of arsenicosis, the present study also advocates that spirulina should be made available and blended into fruit or milk drinks or added to recipes to boost nutritional value, which will increase health and energy. In India spirulina known as "SpiruOm" is well accepted by the children. It is given in extruded noodles, sweetened with sugar to preserve the beta-carotene ${ }^{30}$. In 1974 at the world food conference by the UN spirulina was declared to be the best food for tomorrow ${ }^{34}$. It is commercially produced all over the world including Mexico, California, India, Japan, Thailand, Brazil, and Vietnam. Considering the potential health benefit of the algae the BCSIR has successfully cultured Spirulina. The Government should think and give due attention to spirulina cultivation for utilization of the product locally by the malnourished as well as people suffering from arsenicosis and arsenicosis like problem.

\section{Conclusion:}

It may therefore be concluded that the use of Spirulina could reverse the conditions and restore the patients to normal life. However long term extensive studies are imperative to establish confidently the viability of spirulina for the treatment of arsenicosis. The mechanism of action of spirulina in the treatment and management of chronic arsenicosis if could be known in greater magnitude and could be driven at for setting up its potential benefit, then the present arsenicosis crisis in the form of calamity would be minimized in the near future.

\section{References:}

1. Smith AH, Lingas EO, Rahman M.Contamination of Drinking Water by Arsenic in Bangladesh: a public health emergency. Bulletin of the World Health Organization.2000; 78(9): 1093-1103

2. Haque, MM. Panite Arsenic Tarale Garal (in Bengali) Arsenic in water, poison in liquid. Monograph, Published by Mrs. Nargis Akhter, House no. 92 (A-1), Road no. 11/A: Dhanmondi residential area, Dhaka 2002: pp 1-58

3. McLellan, F. Arsenic contamination affects millions of Bangladesh. Lancet. 2002; 358: 127

4. Abernathy, CO, Calderon RL, Chappal, WR 1997. Arsenic Exposure and Health Effects 1997; Chapman and Hall, London: Ist ed. pp. 1-429

5. Sikder, MS, Maidul, AZM, Ali, M. Rahman, MH. Socioeconomic Status of Chronic Arsenicosis Patients in Bangladesh.Mymensingh Med. J 2005; 14(1): 50-53 
6. Ahmad, K. Report highlights widespread arsenic contamination in Bangladesh. Lancet. 2001; 358: 133

7. Ahmed, M.F. An assessment of arsenic problems in Bangladesh: In International workshop on arsenic mitigation, Dhaka, 2002: pp. 15-20

8. Dillon, JC, Phuc, AP, Dubacq, JP. Nutritional value of the alga spirulina. World Rev. Nutr. Diet. 1995; 77, 32-46

9. Kabir, I. Effect of spirulina on induced chronic arsenicosis in rat. Thesis, 2000; BSMMU

10. Sikder, MS, Maidul, AZ.M, Khan, MAK, Huq MA, Choudhury, SAR, Misbahuddin Effect of Spirulina in the treatment of chronic arsenicosis.Bangladesh J. Dermatol. Venereol. Leprol. 2000; 17: 9-13

11. Islam, AZMM.Spirulina- Personal communication; 2003

12. Rabbani, GH, Das, HK Hossain, A, Ali, SMK, Nasir, M, Chowdhury, AKA Bangladesh Environmental Crisis: Mass arsenic poisoning through contaminated drinking water. 29th Annual Conference, Global Health Council, 2002; May 28-31, Washington, D.C. pp. A 48-A 49

13. Barkat, A, Maksud, AKM, Anwar, KS, Munir, AKM .Social and economic consequences of arsenicosis in Bangladesh. Bangladesh environment; 2002 vol. 1, BAPA, pp. 216-233

14. Jakariya, M, Chowdhury, AMR, Hossain, Z, Rahman, M, Sarker, Q, Khan, RI , Rahman, M. Sustainable communitybased safe water options to mitigate the Bangladesh arsenic catastrophe - an experience from the upzilas. Current Sci. 2003. vol. 85 , no.2, 141-146

15. Sikder, MS, Rahman, MH, Maidul, AZM, Khan, MSU, Rahman, MM. Study on the histopathology of Chronic Arsenicosis. Journal of Pakistan Association of Dermatologists. 2004: 14, 205-209

16. Ahmed, M.F, Minnatullah, KM, Shamsuddin, AL and Ahmed, SA Alternative water supply options. In: Arsenic mitigation in Bangladesh (Ed. Ahmed, M.F. and C.M. Ahmed); 2002: pp 81-174, LGD, LGRD\&C, Dhaka

17. Annapurna, VV, Deosthale, G. Bamji, MS. Spirulina as a source of vitamin A. Plant foods Human Nutrition. In International Workshop of Arsenic Mitigation, January 1416, 1991; 41(2): 125-134

18. Belay, A. and Ota, Y. Current knowledge on potential health benefits of SpirulinaJ. Appl. Phycol. 1993; 5: 235-241

19. Fox, R.D. Spirulina - production and potential. 1996; Published by Edisud, LaCalade, Aixen- Province, France

20. Kay, R.A. Microalgae as food and supplement In Critical Reviews on Food Science and Nutrition. 1991;30 (6): 555571 Published by CRC Press, USA

21. Ciferri, O. Spirulina, the edible organism In Microbiological Reviews. 1983; 2, Dec.: pp 551-578

22. Khan, MAK, Choudhury, SAR. Misbahuddin, M., Maidul, AZM. Sahjahan, M. Effects of Spirulina in the treatment of Chronic Arsenic poisoning in Bangladesh Bang. J. med. sci.
2001; Vol.7, no.1. (Cited in the 'Research Studies on Health Impact of Arsenic Exposure', BMRC, 2002, p 223-231)

23. Guha Mazumder, DN. Treatment of arsenic toxicity as observed in West Bengal J. Int. Med. Asso. 1986 ; 94 (2) : 41-42

24. Hopenhayn-Rich, C., Biggs, ML, Smith, AH, Kalman, DA, Moore, LE Methylation study of a population experimentally exposed to arsenic in drinking water .Environ Health Perspective. 1996; 104: 620-628

25. Huq, IH, Sultana, N., Correll, R. Naidu, R. Arsenic in food chain; 4th International Conference on Arsenic Contamination of Ground water in Bangladesh: cause, effect and remedy. 2002; 12-13 Jan., Dhaka Community Hospital, Bangladesh and School of Environmental Studies, India (cited in 'Research studies on Health Impact of Arsenic Exposure', BMRC, 2002. p 317 : Bang. J. Physiol. Pharmacol. 16(1), 15-16

26. Chowdhury, UK, Biswas, BK, Chowdhury,TR, Samanta,G, Mandal, BK, Basu, GC, Chanda,CR, Lodh, D, Saha,,KC, Mukherjee, S, Roy, S, Kabir,S, Quamruzzaman, Q.Chakraborti, D. Ground water Arsenic Contamination in Bangladesh and West Bengal, India. Environmental Health Perspectives.2000; 108 (5): 393-497

27. Momotaj, H. and Hussain, AZM. Effect of Spirulina on Arsenicosis Patients in Bangladesh.Paper presented in the International Conference at the Columbia University, New York, 2001; November 26-27

28. Rabbani, GH and Saha, SK. Chronic arsenic toxicity through contaminated drinking water in Bangladesh: Magnitude of the problem, health effects and detoxification. The Orion. 2000; 11: 3-7

29. Saha, KC. Arsenicosis in West Bengal (Environmental problems and solution) Sadananda Prakashani, 2002; pp: 117

30. Seshadri, CV. Large scale nutritional supplementation with spirulina alga All India Coordinated Project on Spirulina, 1993 Shri Amm Murugappa Chettiar Research Center (MRCC), Madras, India

31. Watanabe, C, Inaoka,T, Kadono,T Nagano, M., Nakamura, S., Ushijima, K., Murayama, N., Miyazaki, K., Ohtsuka, R Males in rural Bangladeshi communities are more susceptible to chronic arsenic poisoning than females: analysis based on urinary arsenic .Environ Health Perspect. 2001; 109: 1265-1270

32. Ali, SMK, Edib, K, Pramanik, MMK, Alam, AMS,Rabbani, GH, Anwar, KS, Hossain, A, Nasir, M, Saha,SK Nutritional status of patients with arsenicosis in rural Bangladesh.Bangladesh Environment. 2002; vol. 1, pp: 167-184

33. Rahman, MH. Viability of Potential Health benefits of Spirulina in Arsenicosis Management. Dissertation FCPS Department of Dermatology and Venereology, BSMMU. 2005; pp:1-58

34. Henrikson, R. Earth food spirulina, 1997; 3rd ed. pp: 66-67 California, Ronore Enterprises Inc 